\title{
Vertical Accuracy Assessment of SRTM Ver 4.1 and ASTER GDEM Ver 2 Using GPS Measurements in Central West of Tunisia
}

\author{
Ali Chaieb ${ }^{1}$, Noamen Rebai ${ }^{2}$, Samir Bouaziz ${ }^{1}$ \\ ${ }^{1}$ University of Sfax, National School of Engineers of Sfax. LR. EEE (3E), Sfax, Tunisia \\ ${ }^{2}$ University Tunis ElManar, National School of Engineers of Tunis, Tunis, Tunisia \\ Email: "chaieb.aly@gmail.com
}

Received 13 January 2016; accepted 16 February 2016; published 19 February 2016

Copyright () 2016 by authors and Scientific Research Publishing Inc.

This work is licensed under the Creative Commons Attribution International License (CC BY).

http://creativecommons.org/licenses/by/4.0/

cC) (i) Open Access

\begin{abstract}
This paper focuses on the quality of the vertical accuracy of two Digital Elevation Models, corresponding to Kasserine region, central west Tunisia. The vertical accuracy assessment is based on 23 GPS ground control points belonging to the study area. We applied a statistic analysis approach and established 3 elevation profiles corresponding to GPS, ASTER and SRTM. The erected statistical analysis reveals that the Root Mean Squared Error (RMSE) was 8.88 and 10.13 respectively for SRTM and ASTER DTMs. 2D elevation profiles constructed for GPS measurements, ASTER and SRTM, highlight that both DTMs underestimate the true elevation and that SRTM DTM is quite closer to the GPS elevation profile. Relying on this investigation, we think that both DTMs are significant for the vertical accuracy assessment and we urge that SRTM DTM might scheme the Kasserine area features better than ASTER DTM.
\end{abstract}

\section{Keywords}

Vertical Accuracy, Tunisia, DTM, GPS, SRTM, ASTER

\section{Introduction}

The Digital Terrain Model is a representation of continuous elevation values over a topographic surface by a regular array of z-values [1] [2], referenced to a common datum. DTMs are typically used to represent terrain features.

${ }^{*}$ Corresponding author.

How to cite this paper: Chaieb, A., Rebai, N. and Bouaziz, S. (2016) Vertical Accuracy Assessment of SRTM Ver 4.1 and ASTER GDEM Ver 2 Using GPS Measurements in Central West of Tunisia. Journal of Geographic Information System, 8, 5764. http://dx.doi.org/10.4236/igis.2016.81006 
The generation of DTMs can be achieved through two main methods [3]: either a direct collection of field data "direct survey" (e.g. topographical survey by GPS or total station) or remote sensing (e.g. LIDAR and RADAR).

Scientists frequently use the remote sensing rather than direct survey data [4]-[9]. One powerful technique for generating digital elevation models is the interferometric synthetic aperture radar [10] where two passes of a radar satellite (such as RADARSAT-1or TerraSAR-X or Cosmo SkyMed), or a single pass if the satellite is equipped with two antennas (like the SRTM instrumentation). The Advanced Spaceborne Thermal Emission and Reflexion Radiometer-Global Digital Elevation Model (ASTER GDEM) is another possible technique that might be feasible in such a study. The generation of the last two techniques is carried out following a four-step process [11]: source of elevation data; resampling to required grid spacing; interpolation to extract height of required point and DEM representation, editing and accuracy assessment. Each of these steps might be a source of errors [12]. According to [13] errors can be classified into gross errors, systematic errors, and random errors.

\section{Geographical Location}

Geographically the Kasserine region which lies between E, 8.646 to 9.158 and between N, 35.075 to 35.32 (Figure 1), is part of the Tunisian Atlas chain and belongs to central west Tunisia highlands. It is characterized by a relatively high average altitude and embraces the highest point of Chaâmbi mountain in Tunisia (1544 m). The lowest point of this area is $570 \mathrm{~m}$.

\section{Dataset}

For this study we used two types of DTM, SRTM and ASTER GDEM.

\subsection{SRTM}

The Shuttle Radar Topography Mission (SRTM) is a joint project between NASA and NGA (National GeospatialIntelligence Agency) to map the world in three dimensions. The SRTM uses a dual Spaceborne Imaging Radar (SIR-C) and a dual X-band Synthetic Aperture Radar (X-SAR) configured as a baseline interferometer, acquiring two images at the same time. When combined, these images can produce a single 3-D image. Flown aboard the NASA Space Shuttle Endeavour 11-22 February 2000, the SRTM successfully collected data over $80 \%$ of the Earth's land surface, for all the area stretching between latitudes 60 degrees $N$ and 56 degrees S [14].

The SRTM data is being used to generate a digital topographic map of the Earth's land surface [15] with data points spaced every 3 arc second for a Global coverage of latitude and longitude (approximately 90 meters). The SRTM "finished" data meet the absolute horizontal and vertical accuracies of 20 meters (circular error at 90\%

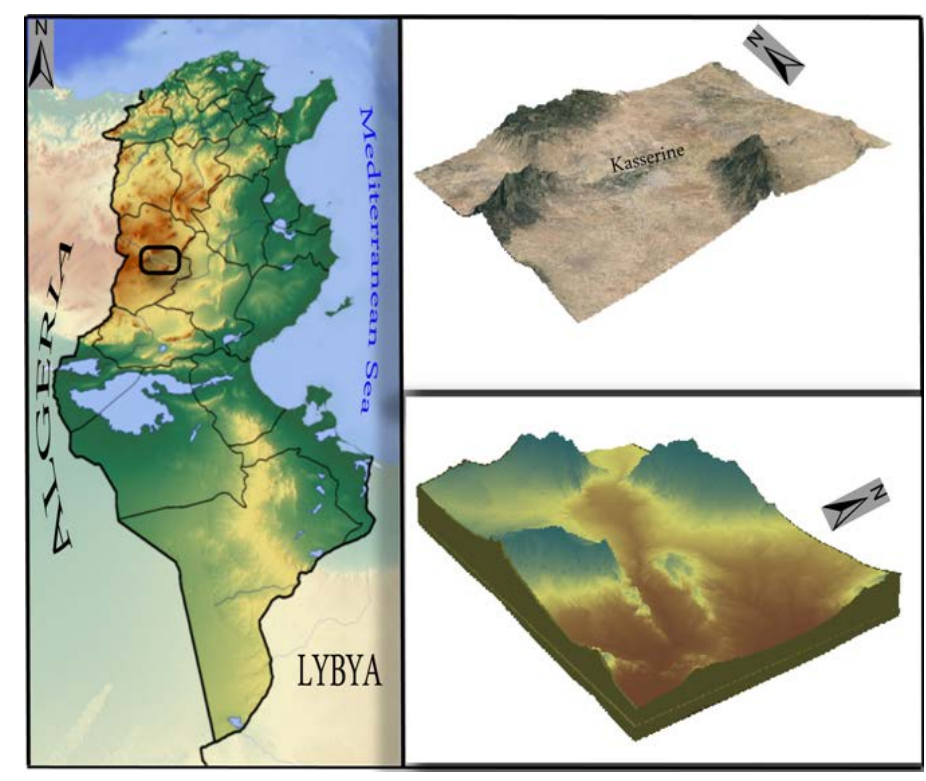

Figure 1. Location of study area. 
confidence) and 16 meters (linear error at $90 \%$ confidence), respectively, as specified by the mission. The vertical accuracy is actually significantly better than 16 meters. It is closer to \pm 10 meters.

\subsection{Aster GDEM}

The Ministry of Economy, Trade, and Industry (METI) of Japan and the United States' National Aeronautics and Space Administration (NASA) jointly announced the release of the Advanced Spaceborne Thermal Emission and Reflection Radiometer (ASTER) Global Digital Elevation Model Version 2 (GDEM V2) on October 17, 2011.

The first version of the ASTER GDEM, released in June 2009, was generated using stereo-pair image collected by the ASTER instrumenting onboard Terra. ASTER GDEM coverage spans from 83 degrees north latitude to 83 degrees south, involving 99 percent of Earth's landmass [16].

The improved GDEM V2 adds 260,000 additional stereo-pairs, improving coverage and reducing the occurrence of artifacts. The refined production algorithm provides improved spatial resolution, increased horizontal and vertical accuracy, and superior water body coverage and detection. The ASTER GDEM V2 maintains the GeoTIFF format and the same gridding and tile structure as V1, with 30-meter postings and $1 \times 1$ degree tiles [17].

Version 2 shows significant improvements over the previous release. However, users are advised that the data contains anomalies and artifacts that will impede effectiveness for use in certain applications. The data are provided "as is", and neither NASA nor METI/Japan Space Systems (J-spacesystems) will be responsible for any damages resulting from use of the data [18].

As a contribution from METI and NASA to the Global Earth Observation System of Systems (GEOSS), ASTER GDEM V2 data are available free of charge to users worldwide from the Land Processes Distributed Active Archive Center (LP DAAC) and J-spacesystems.

\subsection{Reference DEM}

To assess the precision of DTM, SRTM and ASTER GDEM, highly precise field data (at least three times more precise than those test subjects) are required [4]. Actually, we use measurements collected by GPS from the Tunisian Office of Topography and Cadastre. These are very reliable and highly precise measurements. They have also been used in real time kinematic (RTK GPS) with a centimetric precision.

Tunisian OTC affords 23 GPS measurement points, as shown in the (Figure 2), well stretched over the studied

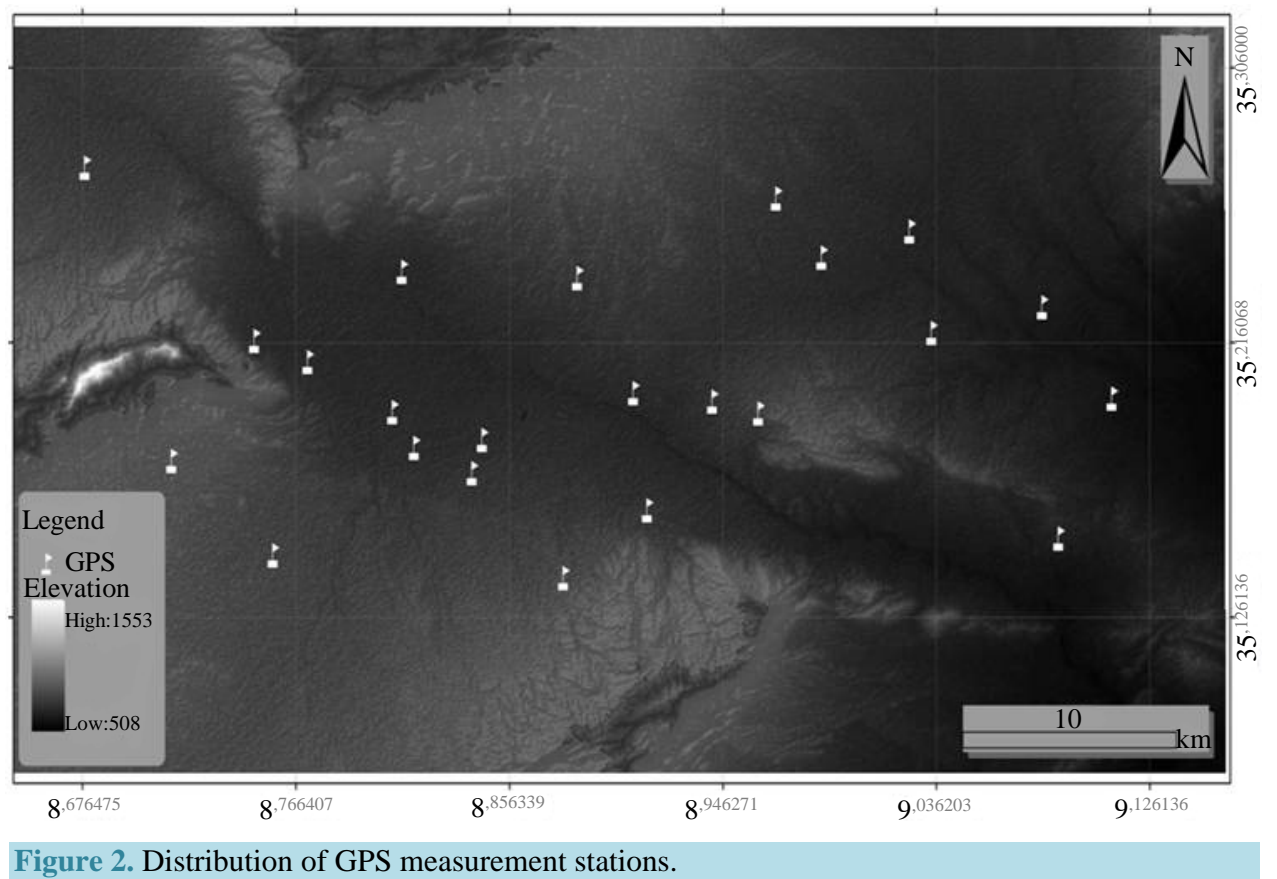


area. For a good accuracy, the Position Dilution of Precision (PDOP) has been respected and did not exceed 2.

\section{Methodology}

A geostatic approach has been applied in this study. To this end, we compare Z-elevation data values that come from GPS and DTM (ASTER GDEM and SRTM). This comparison is based on the mean difference between ZGPS and ZSRTM, ZASTER GDEM and the Root Mean Square Error (RMSE) as well as the Standard Deviation.

To perform this comparison, GPS measurements projected in Universal Transverse Mercator (UTM) system corresponding to ellipsoidal elevation and referred to as World Geoditic System (WGS 84) were converted into horthometric elevation [19]. In this case, the geoid elevation is subtracted from any given GPS row data. Having done so, we ascertain that GPS and DTM data have the same reference vertical datum which is Earth Geopotential Model (EGM 1996) [19]. The transformation process from ellipsoidal to geodetic is accomplished by EGM96 calculator (ver1.0) offered by the National Imagery and Mapping Agency (NIMA) and National Aeronautics and Space Administration (NASA).

In order to evaluate every DTM precision versus GPS data, a Z value is extracted from pixel raster data and compared to ZGPS. This step is performed through Spatial Analyst Tools of Arc GIS software.

Finally, the error distribution between the two DTMs is analyzed using the geostatic package. Error distribution is plotted against a Quantile-Quantile plot in order to underline the relationship between this distribution and the theory model (linear distribution).

Flow chart (Figure 3) below summarizes the paradigm of the methodology applied in this study.

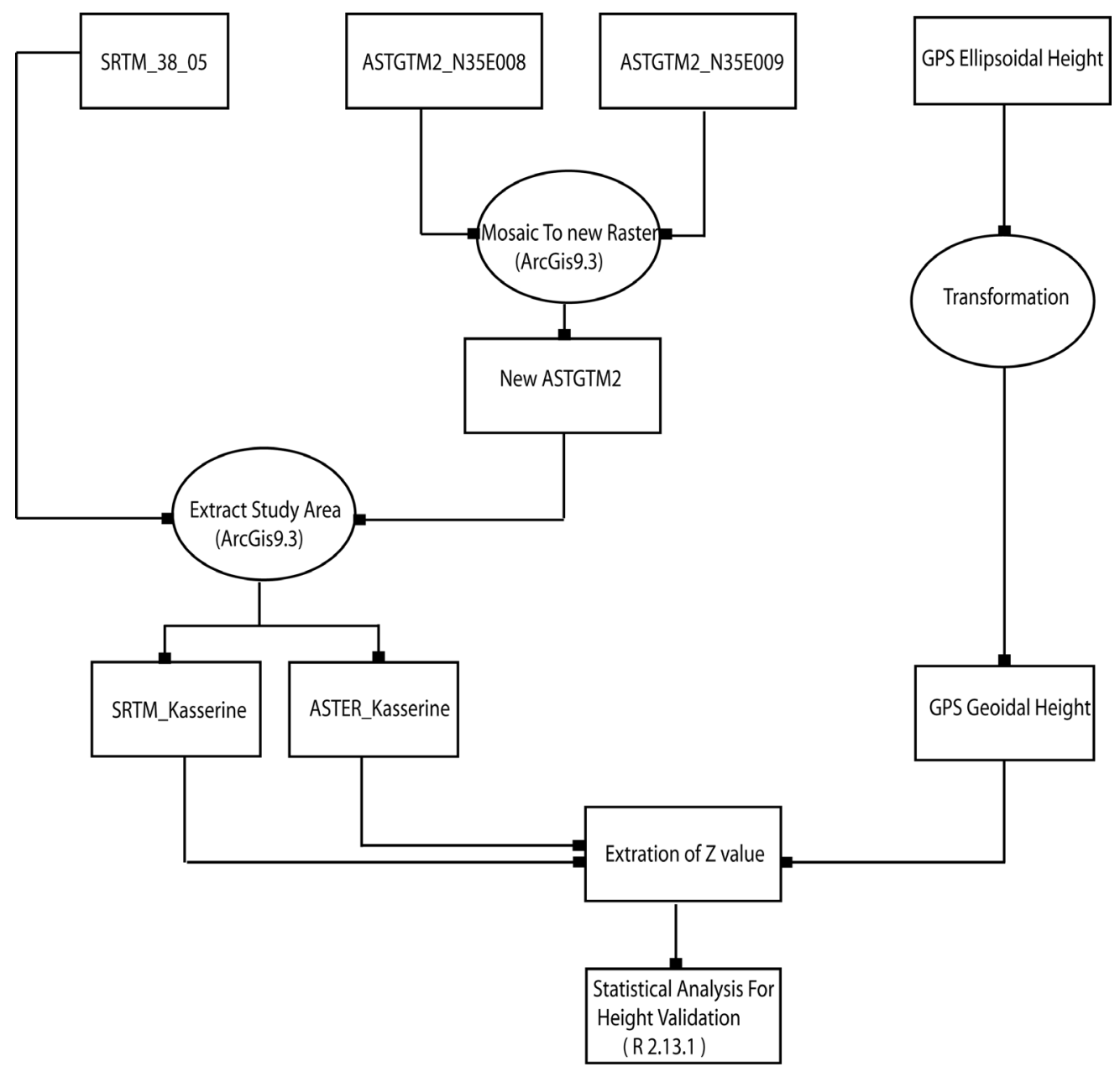

Figure 3. Methodology flow chart. 
Table 1. Statistic summary of GPS measured values, SRTM, and ASTER Z-values.

\begin{tabular}{cccc}
\hline & ASTER GDEM & SRTM & GPS \\
\hline Min & 551 & 552 & 557,424 \\
Max & 875 & 876 & 877,006 \\
Mean & 67,108 & 67,134 & 6732 \\
Count & 23 & 23 & 23 \\
\hline
\end{tabular}

\section{Results and Discussion}

The comparative study between GPS data and SRTM, ASTER GDEM emphasizes an underestimation of the DTMs elevation value as shown in the table below (Table 1). The SRTM documents the lowest mean deviation.

From a statistical point of view, mean difference between GPS and ASTER is -2.11 whereas it is only -1.85 between GPS and SRTM (Figure 4).

Computing of the standard deviation $\sigma=\sqrt{\frac{1}{N-1} \sum_{i-1}^{N}(X i-\bar{x})^{2}}$ is applied to assess the distribution of measurements around a given mean value. In other words, it is an estimation of the mean deviation against the central tendency.

ASTER-GPS standard deviation is 6.78 (Figure 4). Hence, mean deviation is between 4.67 and -8.89 ( -2.11 \pm 6.78 ) while the standard deviation of SRTM-GPS is 9.41 (Figure 4). Hence, the mean deviation ranges between 7.56 and $11.26(-1.85 \pm 9.41)$.

The DTM precision assessment is performed through the compilation of the Root Mean Square Error given as RMSE $=\sqrt{\frac{\sum_{i=1}^{n}(Z o-Z i)^{2}}{n}}$. ASTER computed RMSE value is 10.13 (Figure 4) whereas SRTM computed RMSE value is 8.88 (Figure 4). Relying on this result we urge that the SRTM DTM precision is better and more reliable than that of ASTER DTM.

The plots in Figure 5(a) and Figure 5(b) show a linear and positive slope of both DTMs (Aster and SRTM) and GPS elevation. The existence of this positive relationship (slope) between the two variables (DEMs and GPS elevation) proves that both variables are moving in the same direction.

The correlation coefficient (Figure 5) values help to interpret the existing relationships between the variables (DEMs and GPS elevation) in terms of variations. That is, in the graph of ASTER elevation against GPS elevation, the correlation coefficient is 0.98 . This value indicates that $98.00 \%$ of the changes in Aster elevation are explained by the change of GPS elevation. In the case of SRTM elevation against GPS elevation data, $99.0 \%$ of the changes in the SRTM elevation and GPS elevation could be explained for the study area. Thanks to such a result, we assume that SRTM is slightly better correlated to the reference than ASTER.

The aim of Q-Q plot (Quantile-Quantile) (Figure 6) is to stress the conformity between empirical and theoretical error distribution. Actually, this distribution tends to be conforming with the theoretical one but with some points that show a sigmoidal form (Figure 6).

The elevation profile shown in Figure 7 highlights the similarity of form between all DTMs with a quite slight difference. It shows also again that the SRTM and ASTER profiles underestimate the true measured GPS elevation. Moreover, the SRTM appearance profile is quite the closest to that of the GPS, a result previously outlined by the statistical study.

\section{Conclusions}

Established in the Kasserine area, central west Tunisia, the SRTM and ASTER DEM have been assessed for their vertical accuracy.

Both DEMs show note worthy quality and may be considered appropriate for geomatic applications in the study area.

The comparative analysis with GPS ground control points is 8.88 and 10.13 respectively for SRTM and ASTER in terms of their RMSE which pleads for the SRTM for Kasserine region terrain feature geomatic modeling. 

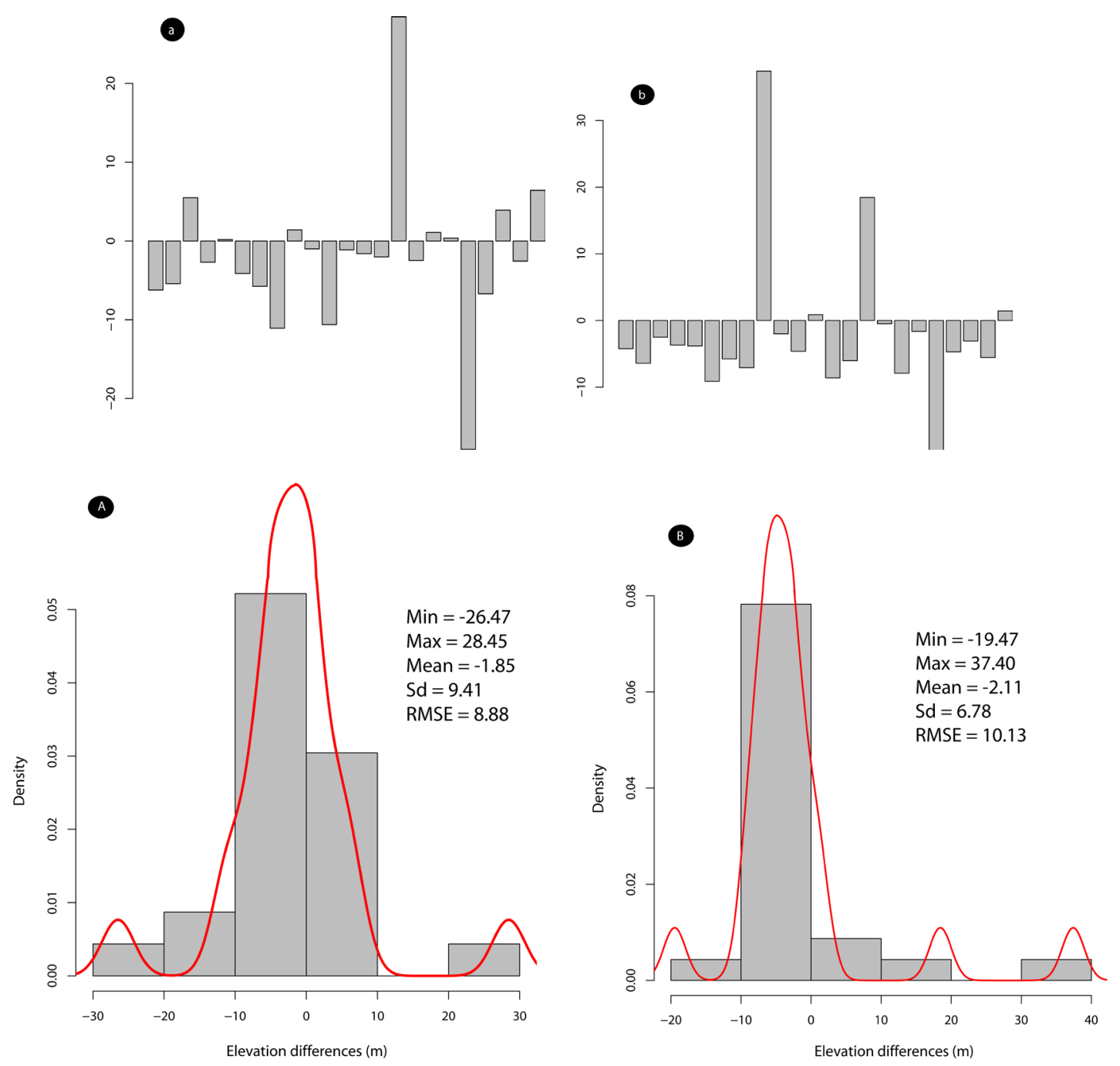

Figure 4. ASTER and SRTM statistic summary. (a) ZSRTM-ZGPS distribution; (A) elevation errors histograms and relevant descriptive statistics relative to the SRTM; (b) ZASTER-ZGPS distribution; (B) elevation errors histograms and relevant descriptive statistics relative to ASTER. The solid red line represents the fitted density curve.
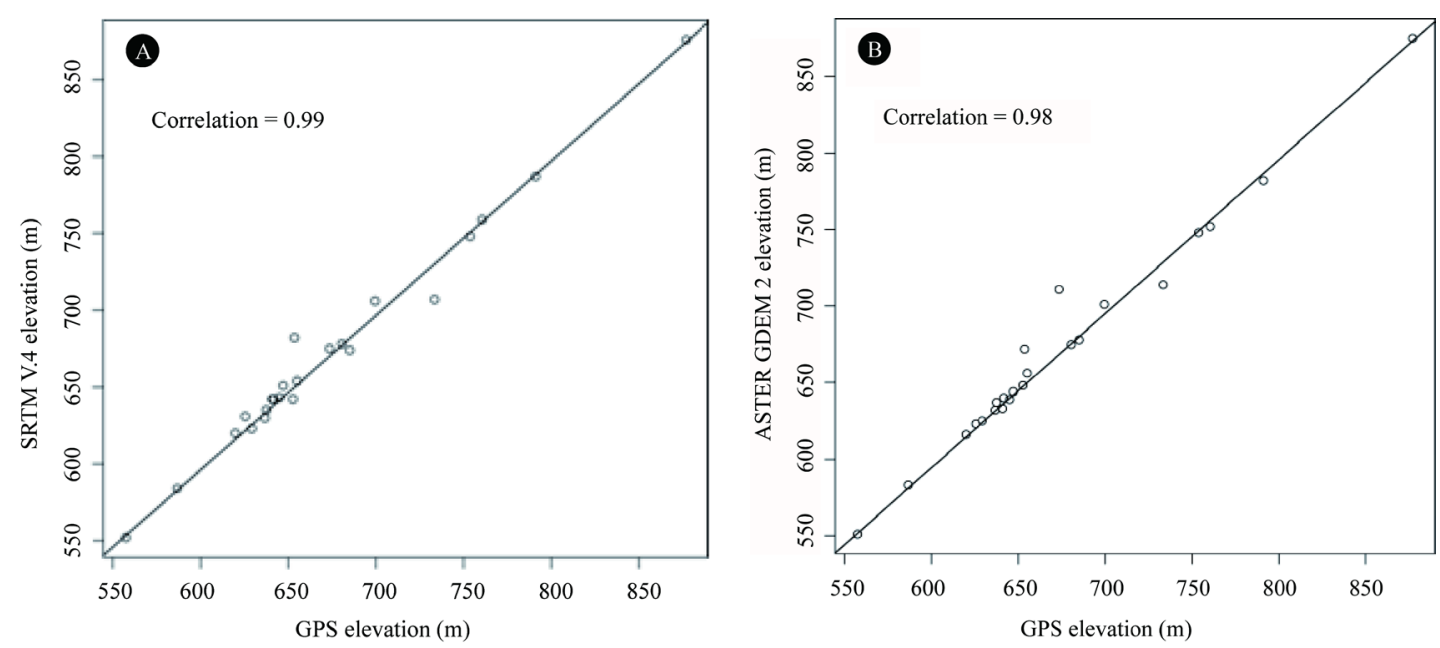

Figure 5. Correlation between Z values. (a) Z GPS vs Z SRTM, (b) Z GPS vs Z ASTER. 

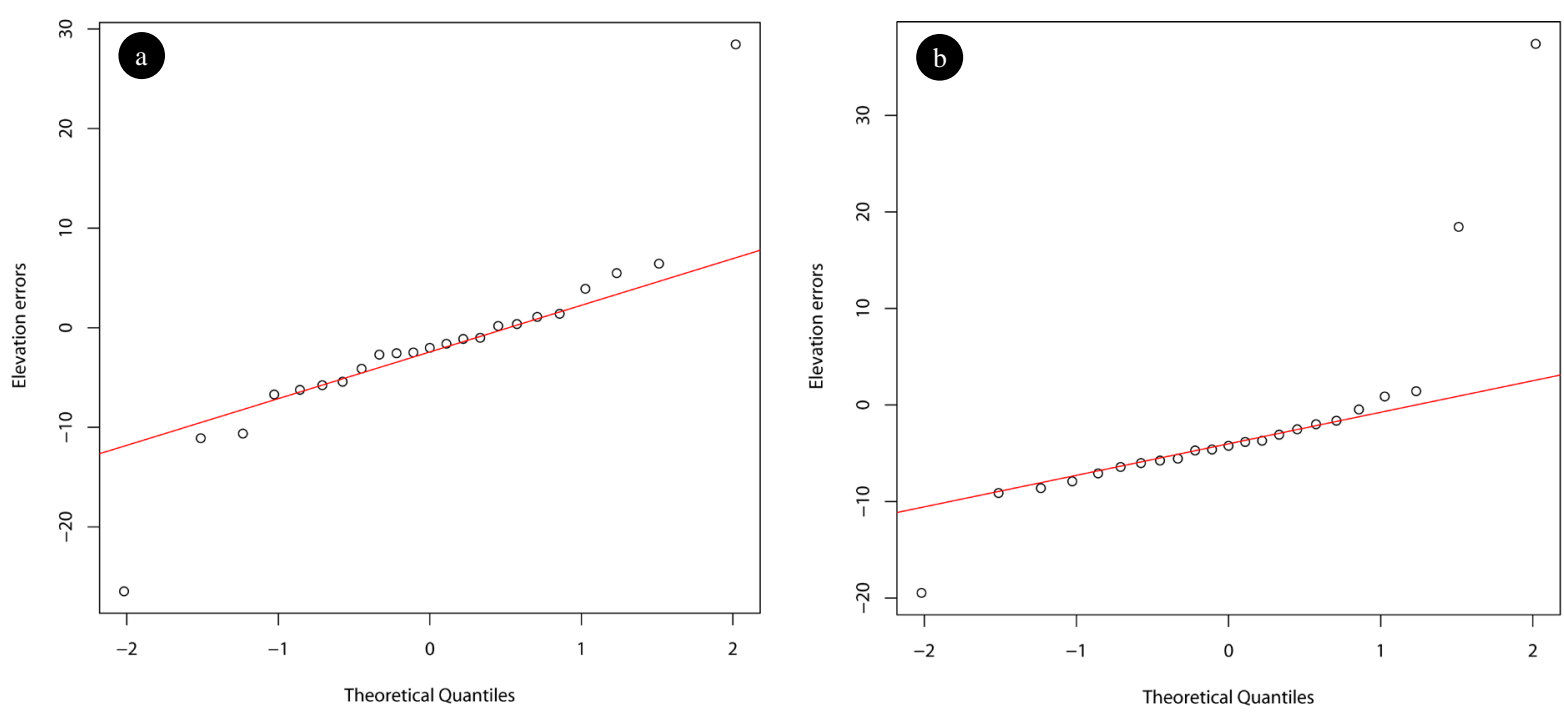

Figure 6. Q-Q plot of Kasserine region showing error distribution for (a) SRTM and (b) ASTER. Solid red line represents theoretical normal distribution.

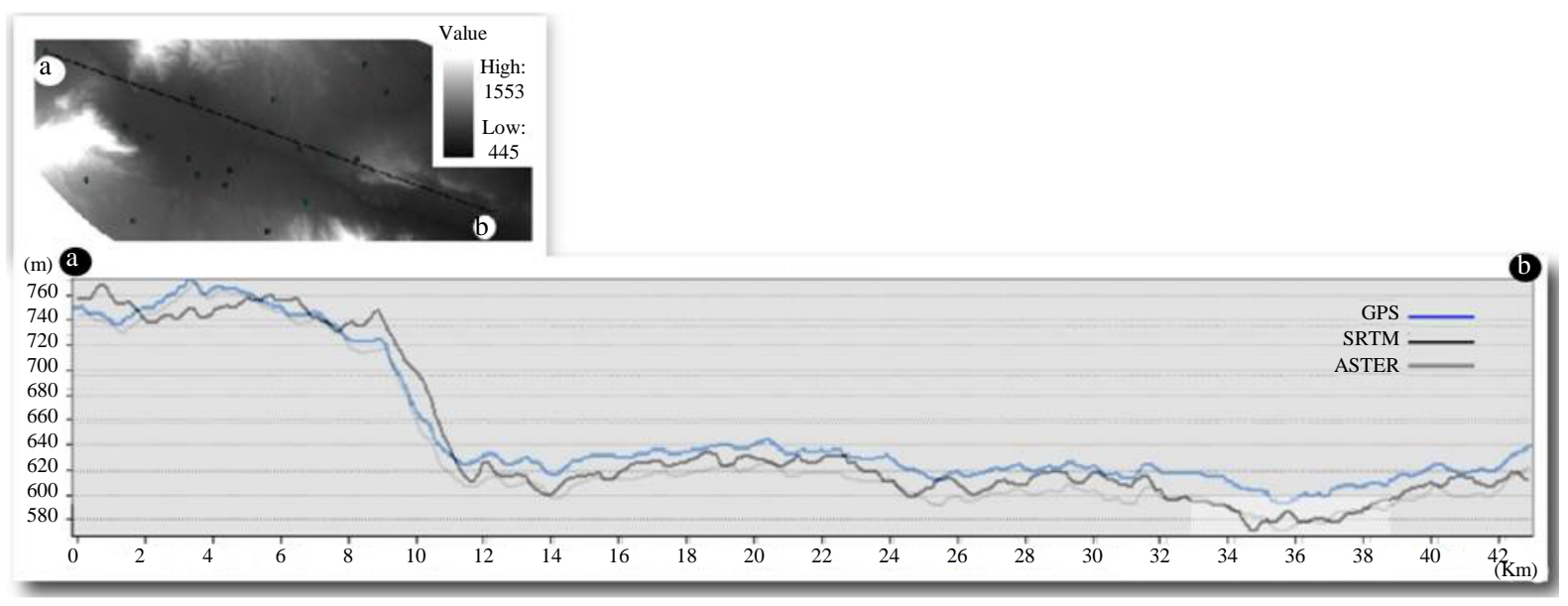

Figure 7. GPS, ASTER and SRTM elevation profiles.

The SRTM good accuracy compared to ASTER in the study area may probably be explained by the absence of a vegetation cover.

\section{Acknowledgements}

Author is thankful to Adel Zafouri for improving the English language of the paper and also is thankful to Tunisian Office of Topography and Cadastre for providing GPS measurement.

\section{References}

[1] Chang, H.C., Li, X. and Ge, L. (2010) Assessment of SRTM, ACE2 and ASTER-GDEM Using RTK-GPS. Proceedings of 15th Australian Remote Sensing \& Photogrammetry Conference, Alice Springs, 13-17 September 2010.

[2] Guth, P.L. (2006) Geomorphometry from SRTM-Comparison to NED. Photogrammetric Engineering \& Remote Sensing, 72, 269-277. http://dx.doi.org/10.14358/PERS.72.3.269

[3] Li, J., Chapman, M.A. and Sun, X. (2006) Validation of Satellite-Derived Digital Elevation Models from In-Track IKONOS Stereo Imagery. Ontario Ministry of Transport, Toronto.

[4] Maune, D.F., Ed. (2007) Digital Elevation Model Technologies and Applications: The DEM User Manual. 2nd Edition, Asprs Pubns, Bethesda, MD. 
[5] Hirt, C., Filmer, M.S. and Featherstone, W.E. (2010) Comparison and Validation of the Recent Freely Available ASTER GDEM ver1, SRTM ver4.1 and GEODATA DEM-9S ver3 Digital Elevation Models over Australia. Australian Journal of Earth Sciences, 57, 337-347.

[6] Miliaresis, G.Ch. and Paraschou, C.V.E. (2005) Vertical Accuracy of the SRTM DTED Level 1 of Crete. International Journal of Applied Earth Observation and Geoinformation, 7, 49-59. http://dx.doi.org/10.1016/j.jag.2004.12.001

[7] Frey, H. and Paul, F. (2012) On the Suitability of the SRTM DEM and ASTER GDEM for the Compilation of Topographic Parameters in Glacier Inventories. International Journal of Applied Earth Observation and Geoinformation, 18, 480-490.

[8] Miliaresis, G.C. and Paraschou, C.V.E. (2011) An Evaluation of the Accuracy of the ASTER GDEM and the Role of Stack Number: A Case Study of Nisiro Island, Greece. Remote Sensing Letters, 2, 127-135. http://dx.doi.org/10.1080/01431161.2010.503667

[9] Ferry, M., Meghraoui, M., Abou Karaki, N., Al-Taj, M., Amoush, H., Al-Dhaisat, S. and Barjous, M. (2007) A 48-kyr-Long Slip Rate History for the Jordan Valley Segment of the Dead Sea Fault. Earth and Planetary Science Letters, 260, 394-406. http://dx.doi.org/10.1016/j.epsl.2007.05.049

[10] Shortridge, A. and Messina, J. (2011) Spatial Structure and Landscape Association of SRTM Error. Remote Sensing of Environment, 115, 1576-1587. http://dx.doi.org/10.1016/j.rse.2011.02.017

[11] Hebeler, F. and Purves, R.S. (2009) The Influence of Elevation Uncertainty on Derivation of Topographic Indices. Geomorphology, 111, 4-16. http://dx.doi.org/10.1016/j.geomorph.2007.06.026

[12] Rexer, M. and Hirt, C. (2014) Comparison of Free High Resolution Digital Elevation Data Sets (ASTER GDEM2, SRTM v2.1/v4.1) and Validation against Accurate Heights from the Australian National Gravity Database. Australian Journal of Earth Sciences, 61, 213-226. http://dx.doi.org/10.1080/08120099.2014.884983

[13] Fisher, P.F. and Tate, N.J. (2006) Causes and Consequences of Error in Digital Elevation Models. Progress in Physical Geography, 30, 467-489. http://dx.doi.org/10.1191/0309133306pp492ra

[14] Jarvis, A., Reuter, H.I., Nelson, A. and Guevara, E. (2008) Hole-Filled SRTM for the Globe Version 4.CGIAR-CSI SRTM 90 m Database. https://srtm.csi.cgiar.org

[15] Slater, J.A., Garvey, G., Johnston, C., Haase, J., Heady, B., Kroenung, G. and Little, J. (2006) The SRTM Data "Finishing” Process and Products. Photogrametric Engineering \& Remote Sensing, 72, 237-244. http://dx.doi.org/10.14358/PERS.72.3.237

[16] Fujisada, H., Bailey, G.B., Kelly, G.G., Hara, S. and Abrams, M.J. (2005) ASTER DEM Performance. IEEE Transactions on Geoscience and Remote Sensing, 43, 2707-2714. http://dx.doi.org/10.1109/TGRS.2005.847924

[17] Team ASTER GDEM Validation (2011) ASTER Global Digital Elevation Model Version 2-Summary of Validation Results. https://lpdaac.usgs.gov/

[18] Slater, J.A., Heady, B., Kroenung, G., Curtis, W., Haase, J., Hoegemann, D., Shockley, C. and Kevin, T. (2009) Evaluation of the New ASTER Global Digital Elevation Model. National Geospatial-Intelligence Agency, Reston.

[19] Mukherjee, S., Joshi, P.K., Mukherjee, S., Ghosh, A., Garg, R.D. and Mukhopadhyay, A. (2013) Evaluation of Vertical Accuracy of Open Source Digital Elevation Model (DEM). International Journal of Applied Earth Observation and Geoinformation, 21, 205-217. http://dx.doi.org/10.1016/j.jag.2012.09.004 